\title{
Referências ao teatro nas Filípicas de Cícero e suas implicações para o ethos de Marco Antônio: a atriz de mimo Volumnia Cytheris.
}

\author{
Bruna Fernanda Abreu*
}

RESUMO: É evidente o teor difamatório das Filípicas de Cícero contra Marco Antônio, uma vez que, nesses discursos, o orador ataca a vida privada e política de seu adversário. O principal objetivo de nosso trabalho é estudar um dos aspectos dessa estratégia difamatória, expondo e analisando alguns trechos das quatorze Filípicas de Cícero para verificar como as referências à atriz de mimo Volumnia Cytheris aparecem neles e de que modo colaboram para a construção da imagem de Marco Antônio como um personagem cômico ele próprio.

Palavras-chave:Cícero; Filípicas; teatro; Marco Antônio; Volumnia Cytheris.

ABSTRACT: It's evident the slanderous content of Cicero's Philipics against Mark Antony, since in these speeches the speaker attacks the private and political life of his adversary. The main objective of our paper is to study a certain aspect of Cicero's strategy presenting and analysing some sections from Cicero's fourteen Philippics in order to verify from them how references to mimo actress Volumnia Cytheris appear and what they mean for the construction of Mark Antony's image as a comic character.

Keywords: Cicero; Philippics; theater; Mark Antony; Volumnia Cytheris.

\section{Introdução}

Como ponto de partida de nosso trabalho, é preciso dizer que a temática do teatro nos discursos de Cícero vai além de sua amizade com Q. Róscio Galo e Clódio Esopo e do discurso Pro Roscio Comoedo. Sobre isso, destacamos o que nos diz Fantham (2008, pp. 427-428):

A juventude de Cícero, quando o drama romano estava já em declínio, coincide com o grande período dos astros, na comédia e na tragédia. Ele estabeleceu uma íntima amizade com o importante comoedus Q. Róscio Galo, assim como conheceu o ator trágico ligeiramente mais jovem Clódio Esopo. Sua intimidade com Róscio é confirmada pelo discurso Pro Roscio Comoedo - defendendo-o de uma acusação de negócios fraudulentos em 66 a.C. -, bem como por suas muitas alusões a conversas pessoais com Róscio e ainda por seus relatos acerca do desempenho de ambos os atores.

\footnotetext{
* Graduada em Letras pela Universidade Estadual de Campinas, mestre e doutoranda em Linguística pelo Instituto de Estudos da Linguagem (IEL) da Unicamp, área Letras Clássicas.
} 
O Pro Roscio Comoedo constitui então uma defesa ${ }^{1}$ por parte de Cícero de um ator de comédia: "O Pro Roscio de Cícero, um discurso em defesa de Róscio, atribui todas as qualidades estereotipadas dos atores ao oponente de Róscio para livrar Róscio de uma acusação de fraude". ${ }^{2} E$ um fato interessante a relação amigável entre Cícero e os atores Róscio e Esopo, uma vez que em De oratore ${ }^{3}$ o orador associa alguns elementos do teatro ao exercício de uma boa oratória. Marshall (2006, p. 128) afirma que em De oratore "Cícero prossegue citando as passagens que ele achou particularmente comoventes no teatro e especula sobre seu impacto emocional no ator". 4 Mencionamos ainda Plutarco, Vidas Paralelas: Cícero, 5:

Diz-se que sua dicção não era menos defeituosa que a de Demóstenes, razão pela qual escutava atentamente o comediante Róscio e o trágico Esopo. A propósito de Esopo, conta-se que o ator, desempenhando no teatro o papel de Atreu, no momento em que este medita sua vingança viu um servidor passar correndo diante dele: como se houvesse perdido o controle sob o império da paixão, golpeou-o com o cetro e matou-o. O vigor de Cícero contribuiu grandemente para a sua facilidade de persuasão. ${ }^{5}$

Sobre a influência da arte da representação na capacidade persuasiva de Cícero, pode-se afirmar que "Róscio costumava competir com Cícero para descobrir qual deles expressaria melhor uma emoção ou uma ideia, Róscio em gestos, Cícero em palavras eloquentes" (DUNCAN, 2006, p. 174). Contudo, a influência da arte na oratória e da oratória na arte era recíproca, já que Róscio e Esopo costumavam frequentar o tribunal para levar gestos forenses ao palco. ${ }^{7}$

Portanto, tomando como exemplo a relação entre Cícero e Róscio, é possível dizer que há muitas referências ${ }^{8}$ positivas ao teatro em Cícero, em relação tanto a atores quanto à própria arte em si, como é o caso da obra De oratore. De fato, podemos dizer que Cícero une o teatro à oratória no âmbito de sua vida pessoal e profissional.

Contudo, não vemos essa referência positiva ao teatro ou aos atores nas quatorze Filípicas de Cícero. Esses discursos, como se sabe, são posteriores ao assassinato de Júlio César e foram escritos contra Marco Antônio. Em sua invectiva, Cícero trata de aspectos da vida política e pessoal de seu oponente, resultando em uma dicotomia na caracterização do ethos, do caráter, de ambas as personas, ou seja, há um antagonismo e uma dualidade em relação à construção da imagem desses dois personagens: Cícero é tudo aquilo o que Marco Antônio não é e vice-versa.

Ao longo desses discursos, quando o orador critica os hábitos da vida pessoal de Marco Antônio, há trechos em que considera seus amigos e companheiros uma má

\footnotetext{
${ }^{1}$ Cf. Lintott (2008, pp. 60-67).

2 “Cicero's Pro Roscio, a speech in defense of Roscius, attributes all of the stereotypical qualities of actors to Roscius' opponent in order to clear Roscius of a charge of fraud” (DUNCAN, 2006, p. 161).

${ }^{3}$ Para algumas referências às características do teatro presentes em De oratore, cf.: CÍCERO, De or. $1.142-143 ; 2.34 ; 2.115-116 ; 2.182 ; 2.193-194 ; 3.213-214 ; 3.216 ; 3.220 ; 3.222-223$.

4 "Cicero proceeds to quote passages he has found particularly moving in the theatre, and speculates on their emotional impact on the actor".

${ }^{5}$ Tradução de Gilson César Cardoso.

6 "Roscius used to compete with Cicero to see which one of them could express an emotion or idea better, Roscius in gestures, Cicero in eloquent words".

${ }^{7}$ Cf. FANTHAM (2008, p. 428).

${ }^{8}$ Para mais informações sobre a relação entre Cícero e o teatro, cf. MANUWALD, G. Roman Republican Theatre. NY: Cambridge University Press, 2011.
} 
companhia, dentre eles: atores e autores de mimo, cafetões, dançarinos, tocadores de cítara, jogadores, alcoviteiros, ou seja, todos aqueles que supostamente $\mathrm{o}$ acompanhavam em orgias, comilanças, jogos de azar e vinho. ${ }^{9}$ Além disso, são de grande importância nas Filípicas as menções de Cícero à atriz de mimo Volumnia Cytheris e a crítica ao fato de ela ser companheira e amante de Marco Antônio.

Sabendo que Cícero se coloca como um perpétuo defensor da República e não aprova muitas das atitudes políticas de Marco Antônio, um dos principais objetivos invectivos do orador nas Filípicas é enfraquecer a imagem de seu adversário. Ao fazer uso da estratégia retórica ${ }^{10}$ de expor e criticar aspectos da vida pessoal/privada de seu adversário a fím de persuadir seu "público", a menção às más companhias e à sua amante atriz de mimo corrobora para a construção de um ethos negativo de Marco Antônio do ponto de vista de Cícero. Desse modo, vamos nos ater à atriz de mimo Volumnia Cytheris e expor alguns trechos das quatorze Filípicas em que há menção a ela. O objetivo, então, é verificar como essas referências à atriz aparecem e de que modo colaboram para a construção da imagem de Marco Antônio.

\section{Sobre a atriz Volumnia Cytheris}

Antes de examinarmos os trechos das Filípicas em que a atriz de mimo Volumnia Cytheris é citada, é de fundamental importância que levantemos considerações biográficas sobre ela. Podemos afirmar, segundo o Brill's New Pauly, que Cytheris é

O nome artístico descritivo ("pertencente a Afrodite") de uma atriz de mimo romana (mima) do $1^{\circ}$ século a.C.; comprada da escravidão por Volumnius Eutrapelus, seu nome oficial era Volumnia (Cic. Phil. 2.58). Não se sabe nada sobre suas performances do palco, mas, sobretudo, sobre suas qualidades eróticas. Ela alcançou a notoriedade como amante de Antônio: antes de seu casamento com Fúlvia em 47, ela o acompanhou em suas aparições públicas em uma liteira aberta. ${ }^{11}$

A figura da atriz de mimo Volumnia Cytheris também aparece em Plutarco, Vidas Paralelas: Antônio, 9:

Havia também o mímico Sérgio, muito prestigiado por ele, e uma mulher que amava, Citéris, integrante da mesma companhia de atores. Para onde quer que fosse levava-a numa liteira, acompanhada pelo mesmo número de criados que a da mãe de Antônio. ${ }^{12}$

Além disso, o próprio Cícero, em Ad Atticum, ${ }^{13}$ também menciona Volumnia Cytheris em três passagens:

\footnotetext{
${ }^{9}$ Cf. os trechos das Filípicas: 2.15, 2.20, 2.58, 2.61-63, 2.67, 2.69, 2.101, 5.15, 8.26, 11.13, 13.24.

${ }^{10}$ Sobre a captatio beneuolentiae com base na pessoa do adversário, cf. Cic. Inv. 1.20; 1.22; e Rhet. Her.1.7-8.

11 'Descriptive artist's name ('belonging to Aphrodite') of a Roman mime actress (mima) of the 1st cent. BC; bought out of slavery by Volumnius Eutrapelus, her official name was Volumnia (Cic. Phil. 2,58). Nothing is known about her stage performances, but all the more about her erotic qualities. She attained notoriety as mistress of Antonius: before his marriage to Fulvia in 47 she accompanied him on his public appearances in an open litter".

${ }^{12}$ Tradução de Gilson César Cardoso.

${ }^{13}$ As traduções dos trechos de Ad Atticum são nossas.
} 
"Contudo, este [Antônio] carrega consigo em uma liteira aberta Cytheris, a outra esposa". (CÍCERO, Att. 10.10.5) ${ }^{14}$

"Certamente, isto é melhor do que nosso colega Antônio, cuja atriz de mimo é carregada em um liteira entre lictores". (CÍCERO, Att. 10.16.5) ${ }^{15}$ "porém, este nosso Citério". (CÍCERO, Att. 15.22) ${ }^{16}$

É pertinente mencionar o que nos diz Panayotakis (2006, p. 133):

$\mathrm{O}$ adjetivo mima (junto com o diminutivo pejorativo mimula) e o nome próprio Cytheris que Cícero geralmente emprega para se referir a essa mulher (...) claramente fizeram parte de sua venenosa invectiva contra seu inimigo político Marco Antônio, que se tornou o amante de Cytheris, e era sarcasticamente chamado por Cícero de Cytherius. ${ }^{17}$

Além disso, em Ad Familiares, ${ }^{18}$ Cícero "comenta a aparição de Cytheris em um espetáculo público e, então, caracteriza-a como uma mulher que circula entre homens". ${ }^{19}$ Para o orador, "ela é a atriz de mimo Cytheris, uma mulher liberta de nome grego e moral duvidosa que é apropriadamente comercializada entre homens". ${ }^{20}$

Contudo, outro dado importante a ser considerado é que Volumnia Cytheris seria, segundo Sérvio, ${ }^{21}$ a Lycoris de Cornélio Galo, pai da elegia erótica romana. Em comentário à décima Écloga ${ }^{22}$ de Virgílio, Sérvio afirma que Cornélio Galo "escreveu quatro livros de amor sobre sua Cytheris" (amorum suorum de Cytheri descripsit libros quattuor, ad Buc. 10.1), "a quem chamou de Lycoris" (quam Lycorin uocat, ad Buc. 10.6). Sérvio também nos diz que devemos subentender "Lycoris por 'Cytheris'; pois é permitido aos poetas colocar outros nomes no lugar de outros" (Lycoris pro 'Cytheris'; licet enim poetis alia nomina pro aliis ponere, ad Buc. 10.2). ${ }^{23}$

Em outras fontes podemos encontrar demais referências a esse relacionamento entre Lycoris/Cytheris e Cornélio Galo:

\section{"e quantas chagas por Licóris bela Galo \\ Lavou há pouco em águas infernais!" \\ (PROPÉRCIO, 2.34.91-92) ${ }^{24}$}

\footnotetext{
${ }^{14}$ Hic tamen Cytherida secum lectica aperta portat, alteram uxorem.

${ }^{15}$ hoc quidem melius quam conlega noster Antonius, cuius inter lictores lectica mima portatur

${ }^{16}$ hic autem noster Cytherius

17 "The adjective mima (along with the pejorative diminutive mimula) and the proper name Cytheris that Cicero usually employs when referring to this woman (...) clearly formed part of his venomous invective against his political enemy Mark Antony, who became Cytheris' lover, and was sarcastically called by Cicero Cytherius".

${ }^{18}$ Cf. CÍCERO, Fam. 9.26.1-2.

19 "As in his later invective, moreover, he comments on Cytheris' appearance in a public spectacle and thus characterizes her as a woman who circulates among men. (...) she is Cytheris the mime-actress, a freedwoman of Greek name and dubious morals who is appropriately trafficked between men" (KEITH, 2011, p. 44).

${ }^{20}$ Ibid.

${ }^{21}$ Cf. Enciclopedia Virgiliana, p. 216.

${ }^{22}$ Cf. Virgílio, Ecl. 10.1-3:

Extremum hunc, Arethusa, mihi concede laborem: pauca meo Gallo, sed quae legat ipsa Lycoris, carmina sunt dicenda: neget quis carmina Gallo?

${ }^{23}$ Os trechos citados de Sérvio são de nossa tradução.

${ }^{24}$ et modo formosa quam multa Lycoride Gallus mortuus inferna uulnera lauit aqua! (trad. Guilherme Gontijo Flores).
} 
"e Galo, Galo pelos hespérios e pelos orientais será conhecido e com Galo será conhecida a sua Licóride"

(OVÍDIO, Am.1.15.29-30) ${ }^{25}$

"Não foi vergonhoso a Galo ter celebrado Licóride, Mas não ter freado a língua por excesso de vinho"

(OVÍDIO, Tr.2.445-446) ${ }^{26}$

"a bela Licóris era o engenho de Galo" $\left(\right.$ MARCIAL, 8.73.6) ${ }^{27}$

Vemos que essas fontes relacionam Cornélio Galo a Lycoris, que, considerando os comentários de Sérvio, corresponderia à amante de Marco Antônio, Volumnia Cytheris: "Este Galo, porém, amou a meretriz Cytheris, liberta de Volúmnio, a qual, desprezando-o, acompanhou Antônio em sua ida às Gálias" (hic autem Gallus amauit Cytheridem meretricem, libertam Volumnii, quae, eos preto, Antonium euntem ad Gallias est secuta, ad Buc. 10.1). Assim, é possível afirmar que, na leitura de Sérvio, na décima bucólica Virgílio estaria aludindo ao fato de Volumnia Cytheris ter abandonado Cornélio Galo para acompanhar Antônio. Também é interessante mencionar que Sérvio a considera uma meretrix. Apesar de seu relacionamento com Cornélio Galo constituir um dado pertinente para a persona da atriz de mimo, todavia o que nos interessa aqui é o seu relacionamento pessoal com Marco Antônio e o modo como ele é exposto nas Filípicas de Cícero.

Além disso, um dado pertinente é que, em Pro Caelio, discurso anterior às Filípicas, Cícero faz uso do adjetivo meretrix ${ }^{28}$ ao associá-lo a Clódia e, ao caracterizála dessa forma, o orador faz referência ao mimo, único espetáculo teatral em que as mulheres podiam atuar. Segundo Maurício (2013, pp. 36-37),

na exploração de aspectos teatrais na forma como o caso vai sendo apresentado, à descida do género dramático mais nobre - a tragédia - a outro menos elevado - a comédia -, seguir-se-á o rebaixamento àquele que era considerado o mais reles - o mimo. Será sobretudo a narrativa da história dos banhos, uma verdadeira farsa, recheada de ironia e sarcasmo, a recriar uma representação desse género, cuja invenção o orador atribui a Clódia (haec tota fabella ueteris et plurimarum fabularum poetriae), reduzindo-a assim a escritora de mimos - e mimos de má qualidade (e o facto de os mimos contarem com a participação frequente de prostitutas também remete para a sua caraterização como meretrix).

E, ainda, conforme nos diz Nótari (2013, p. 211),

Cícero "frequentemente produzia um impacto expressado no risus mimicus através da obscenidade. (...) A caracterização de Clódia como

\footnotetext{
${ }^{25}$ Gallus et Hesperiis et Gallus notus Eois, et sua cum Gallo nota Lycoris erit (trad. Lucy Ana de Bem).

${ }^{26}$ Non fuit opprobrio celebrasse Lycorida Gallo, sed linguam nimio non tenuisse mero (trad. Patrícia Prata).

${ }^{27}$ ingenium Galli pulchra Lycoris erat (tradução nossa).

${ }^{28}$ Cf. CÍCERO, Pro Caelio, 1, 37, 48, 49, 50 e 57.
} 
meretrix constitui o contraste perfeito com a imagem da obediente matrona que cuida da pureza da sua casa. O comportamento e a aparência de Clodia se encaixam com o de uma meretrix e não com o de uma materfamilias". ${ }^{29}$

Contudo, as referências de Cícero a Volumnia Cytheris nos trechos das cartas a Ático citadas anteriormente "antecipam, então, aquelas em suas invectivas Filípicas não apenas na sua apresentação dos 'fatos', mas também na sua estratégica representação das relações de Antônio com Cytheris para simbolizar a perversão de seus vínculos políticos e sociais com outros homens". 30 De fato, o que Cícero diz em cartas a Ático sobre a atriz de mimo e Marco Antônio é estrategicamente reforçado e desenvolvido em suas Filípicas.

Desse modo, a atriz tem um papel importante nas Filípicas e sua imagem é traçada de modo a difamar Antônio, "que tinha a mesma afinidade que Sila com os profissionais de entretenimento". "Como exemplos do gênero retórico da invectiva, as Filípicas foram cuidadosamente moldadas para impugnar a reputação do oponente político de Cícero e, nisso, certamente foram bem-sucedidas"; 32 as menções à atriz de mimo são um dos elementos desse ataque à reputação de Antônio.

\section{A presença da atriz nas Filípicas}

Nas Filípicas, ${ }^{33}$ a atriz de mimo aparece primeiramente em Phil. 2.20:

"Mas ainda quiseste parecer espirituoso em alguma ocasião. Como isso, bons deuses, não convinha a ti! Nisso, há alguma culpa tua. De fato, tu poderias ter tomado algum gracejo da atriz de mimo, tua esposa". (CÍCERO, Phil. 2.20, grifos nossos) ${ }^{34}$

$\mathrm{O}$ orador sarcasticamente se refere à atriz de mimo, mima, Cytheris como uma altera uxor de Antônio. A crítica, aqui, consiste no fato de Antônio exibir sua amante, expondo, assim, sua depravação (flagitiose) como se ela fosse sua outra esposa; Antônio, então, seria bígamo, algo vedado na lei romana. Desnecessário dizer também que a atriz não era, legalmente, uxor; Cícero sugere que Antônio trata como esposa legítima uma mulher cujo estatuto na sociedade romana era baixo. Assim, segundo Keith (2011, p. 44), quando Cícero a designa "a outra esposa", subentende-se a ilegitimidade moral de Antônio.

Nas seções 58, 61 e 62 da segunda Filípica, Cícero cita novamente Cytheris:

\footnotetext{
29 “frecuentemente producía un impacto expresado en la risus mimicus a través de la obscenidade. (...) La caracterización de Clodia como meretrix constituye el contraste perfecto con la imagen de la obediente matrona que cuida la pureza de su hogar. La conducta y apariencia de Clodia encaja con el de una meretrix y no con el de una materfamilias" (NÓTARI, 2013, p. 211).

30 "Cicero's references to Cytheris in these letters to Atticus thus anticipate those in his invective Philippics not only in their presentation of the 'facts', but also in their strategic representation of Antony's relations with Cytheris to figure the perversion of his political and social bonds with other men" (KEITH, 2011, p. 44).

31 “Antony, who had the same affinity as Sulla with professional entertainers, engaged in a long standing and much publicized affair with the famous mime actress Volumnia Cytheris” (JORY, 1988, p. 78).

32 "As instances of the rhetorical genre of invective, the Philippics were carefully shaped to impugn the reputation of Cicero's political opponent and in this they certainly succeeded" (KEITH, 2011, p. 42).

${ }^{33} \mathrm{~A}$ tradução dos trechos das Filípicas citados aqui é de nossa autoria.

${ }^{34}$ At etiam quodam loco facetus esse uoluisti. Quam id te, di boni, non decebat! In quo est tua culpa non nulla. Aliquid enim salis a mima uxore trahere potuisti.
} 
O tribuno da plebe era transportado numa carruagem; os litores laureados o precediam; entre eles, em uma liteira descoberta, era levada uma atriz de mimo, a quem homens honrados, cidadãos de diferentes municípios, que saíam das cidades e vinham a seu encontro forçosamente, saudavam não por aquele nome conhecido e empregado nos mimos, mas por Volúmnia. Uma carruagem com cafetões seguia, comitiva de homens imprestáveis. A mãe, atrás, seguia a amante do filho impuro como se esta fosse a nora. Oh! fecundidade calamitosa da miserável mulher! (CÍCERO, Phil. 2.58, grifos nossos) ${ }^{35}$

Tu vieste a Brundísio, certamente para o regaço e para o abraço da tua atrizinha de mimo. ${ }^{36} \mathrm{O}$ que há? Por acaso eu minto? Quão infeliz é não poder negar o que é muito vergonhoso confessar! Se tu não te envergonhavas diante dos municípios, nem mesmo diante do exército de veteranos? Pois qual é o soldado que não a tenha visto em Brundísio? Quem não sabia que ela tinha vindo em uma jornada de tantos dias para te felicitar? Quem não sofria por tão tarde ele mesmo descobrir que não vale coisa alguma o homem que havia seguido? (CÍCERO, Phil. 2.61, grifos nossos $)^{37}$

Outra vez houve uma perambulação pela Itália com a mesma atriz de mimo como companheira de viagem. (CÍCERO, Phil. 2.62, grifos nossos) $)^{38}$

Vemos que há a referência ao fato de a atriz acompanhar Antônio como se fosse sua companheira oficial, isto é, membro da comitiva (comes) e ao transporte, numa liteira, da atriz de mimo cuja imagem, segundo Ramsey (pp. 245-246), era maculada pela infâmia associada a suas performances no palco. As pessoas a cumprimentavam pelo nome Volumnia por este ser mais respeitável. ${ }^{39}$ É evidente que Cícero expõe, indiretamente, a infâmia (flagitium), a vergonha (turpitudinem) e a desonra (dedecus) de Antônio. Pode-se dizer que a infâmia de Cytheris também afeta a imagem de Antônio aqui, Cícero questiona quem o cerca. Keith (2011, p. 42) nos diz:

Nesta imagem intencionalmente prejudicial do desempenho de Marco Antônio em relação aos seus deveres administrativos, Cícero descreve Antônio aparecendo em público em negócios oficiais e flanqueado por veículos de luxo (o essedus e raeda) associados a mulheres e aos soldados; acompanhado por sua namorada, uma atriz de mimo manchada

\footnotetext{
${ }^{35}$ Vehebatur in essedo tribunus pl.; lictores laureati antecedebant, inter quos aperta lectica mima portabatur, quam exoppidis municipales homines honesti ob uiam necessario prodeuntes non noto illo et mimico nomine, sed Volumniam consalutabant. Sequebatur raeda cum lenonibus, comites nequissimi; reiecta mater amicam impuri filii tam quam nurum sequebatur. O miserae mulieris fecunditatem calamitosam!

${ }^{36}$ É importante chamar atenção, aqui, para a posição enfática do pronome possessivo "tua" no trecho "tua atrizinha de mimo".

${ }^{37}$ Venisti Brundisium, in sinum quidem et in complexum tuae mimulae. Quid est? num mentior? Quam miserum est id negare non posse, quod sit turpissimum confiteri! Si te municipiorum non pudebat, ne ueterani quidem exercitus? Quis enim miles fuit, qui Brundisi illam non uiderit? quis qui nescierit uenisse eam tibi tot dierum uiam gratulatum? quis, qui non indoluerit tam sero se, quam nequam hominem secutus esset, cognoscere?

${ }^{38}$ Italiae rursus percursatio eadem comite mima.

${ }^{39}$ Cf. também Sussman (1994, p. 78).
} 
com a desvantagem legal (infamia) conferida pela associação com o palco, e alcoviteiros, que eram considerados como uma companhia ainda menos respeitável que as atrizes; e deixando de mostrar a sua mãe e, por implicação, a sua esposa (Antônia) o devido respeito. ${ }^{40}$

Também é interessante destacar a seção 67 da segunda Filípica:

67. Qual Caríbdis foi tão voraz? Caríbdis, eu digo; que, se existisse, seria um animal único; o oceano, por Júpiter, dificilmente poderia ter engolido em tão pouco tempo todas as coisas tão dispersas e distribuídas em lugares tão distantes. Nada estava fechado, nada selado, nada mencionado por escrito; todas as adegas eram entregues aos homens mais inúteis; os atores de mimo apoderavam-se de algumas coisas, as atrizes de outras; a casa estava cheia de jogadores, cheia de bêbados; estava-se a beber dias inteiros, e isso em muitíssimos lugares; além disso, frequentemente sofriam-se - pois nem sempre ele tinha sorte - prejuízos nos jogos de azar; podia-se ver nas celas dos escravos as camas preparadas com as guarnições de leito de Gneu Pompeu tingidas de púrpura. Por conta disso, cessai de admirar-vos por tudo ter sido consumido tão rapidamente. Tanta imoralidade poderia ter consumido rapidamente não só o patrimônio, embora grande, como aquele era, de uma pessoa, mas também cidades e reinos. Mas o mesmo consumiuainda casas e jardins! (CÍCERO, Phil. 2.67, grifos nossos) ${ }^{41}$

Cícero critica o desperdício de dinheiro por parte de Antônio com o grande volume de vinho, ótima prata, vestes caras e esplêndida mobília, uma vez que dissipou os bens de Pompeu em poucos dias. Considera-o, comparativamente, mais destruidor que Caríbdis, que, segundo a mitologia, era um monstro marinho que engolia tudo o que passava à sua frente, ${ }^{42}$ e expõe as imoralidades (nequitia) de Antônio em relação, por exemplo, à bebedeira, à companhia de atores e atrizes de mimo e ao vício nos jogos de azar. Para Cícero, é evidente que Antônio não se comporta como deveria e dá seus bens a atores e atrizes de mimo.

Na seção 69, ainda da segunda Filípica, temos:

\footnotetext{
40 "In this designedly prejudicial picture of Marc Antony's performance of his administrative duties, Cicero describes Antony appearing in public on official business in, and flanked by, luxury vehicles (the essedus and raeda) associated with women and wastrels; accompanied by his girlfriend, a mime-actress tainted with the legal disadvantage (infamia) conferred by association with the stage, and pimps, who were regarded as even less respectable company than actresses; and disdaining to show his mother and, by implication, his then wife (Antonia), due respect".

${ }^{41}$ 67. Quae Charybdis tam uorax? Charybdim dico; quae si fuit, animal unum fuit; oceanus, medius fidius, uix uidetur tot res tam dissipatas, tam distantibus in locis positas, tam cito absorbere potuisse. Nihil erat clausum, nihil obsignatum, nihil scriptum; apothecae totae nequissimis hominibus condonabantur; alia mimi rapiebant, alia mimae; domus erat aleatoribus referta, plena ebriorum; totos dies potabatur, atque id locis pluribus; suggerabantur etiam saepe - non enim semper iste felix - damna aleatoria; conchyliatis Cn. Pompei peristromatis seruorum in cellis lectos stratos uideres. Quam ob rem desinite mirari haec tam celeriter esse consumpta. Non modo unius patrimonium quamuis amplum, ut illud fuit, sed urbis et regna celeriter tanta nequitia deuorare potuisset. At idem aedis etiam et hortos.

${ }^{42}$ Caríbdis pode ser considerado uma espécie de redemoinho de água ou um redemoinho em um canal estreito do mar. Na mitologia, era um monstro disforme, espécie de redemoinho marinho que engolia tudo o que passava pelo estreito de Messina. Cf. OCD, charybdis in: HORNBLOWER, S; SPAWFORTH, A. The Oxford classical dictionary. 4rd ed. Oxford; New York, NY: Oxford University Press, 2012; e Dicionário Etimológico da Mitologia Grega, caríbdis, caribde.
} 
Não queirais fazer perguntas; tornou-se um homem honrado: ele ordenou que aquela sua atrizinha de mimo recolhesse todas as suas coisas, segundo exigiam as Doze Tábuas, tomou a chave. Além disso, quão notável cidadão, quão prezado aquele em cuja vida toda nada há de mais honroso do que o divórcio de uma atriz de mimo. (CÍCERO, Phil. 2.69, grifos nossos $)^{43}$

De modo irônico, com a menção ao divórcio, o orador trata a atriz de mimo como se fosse realmente uma esposa infame de Antônio. Ainda é possível inferir que Antônio trata como esposa legítima quem não era e temos, então, uma espécie de simulacro de divórcio legal, que, na verdade, não possuía nenhum valor legal. E a ironia continua na seção 77:

Mas vede a frivolidade do homem. Quando quase na décima hora do dia ele havia chegado até Saxa Rubra, escondeu-se em certa taverninha e aí, ocultando-se, embebedou-se até ao cair da noite. De lá, na sege de duas rodas, rapidamente foi trazido até a cidade e chegou a casa com a cabeça coberta. O porteiro diz: "Quem és tu?" - "Um mensageiro de Marco". Imediatamente ele é conduzido até a mulher que é o motivo pelo qual viera e lhe entregou uma carta. Quando ela a leu, chorando - pois fora escrita de modo a inspirar amor; mas a essência da carta era que daqui em diante ele nada teria a ver com aquela atriz de mimo, ele tinha descartado todo o seu amor por ela e o transferido para esta - quando a mulher chorou mais copiosamente, o homem compassivo não pôde suportar, descobriu a cabeça e se atirou ao pescoço dela. (CÍCERO, Phil. 2.77 , grifos nossos) $)^{44}$

A cena acima descrita por Cícero, uma reconciliação entre Antônio e Fúlvia, contém certa comicidade que pode ser associada ao teatro. Segundo Sussman (1994, pp. $55-56)$,

Esta seção em particular rigorosamente se assemelha a paraklausithyron e narra a viagem de Antônio da Gália para casa, vestido com roupas incomuns, para realizar, dentre outros objetivos, uma reconciliação com sua esposa Fúlvia (...). Exclusivamente nesta breve passagem, encontramos Antônio em muitas das personae e situações de comédia. Ele é um bêbado em uma roupa ridícula, um jovem apaixonado por uma meretrix, um marido arrependido e galanteador, um seruus currens. Nós encontramos os ingredientes cômicos de uma taverna comum, uma paixão erótica, um amor frustrado, uma identidade escondida, uma cena

\footnotetext{
${ }^{43}$ Nolite quaerere; frugi factus est; mimulam suam suas res sibi habere iussit, ex duodecim tabulis clauis ademit, exegit. Quam porro spectatus ciuis, quam probatus! Cuius ex omni uita nihil est honestius, quam quod cum mima fecit diuortium.

${ }^{44}$ At uidete leuitatem hominis. Cum hora diei decima fere ad Saxa rubra uenisset, delituit in quadam cauponula atque ibi se occultans perpotauit ad uesperam; inde cisio celeriter ad urbem aduectus domum uenit capite obuoluto. Ianitor: 'Quis tu?' 'A Marco tabellarius.' Confestim ad eam, cuius causa uenerat, [deducitur] eique epistulam tradidit. Quam cum illa legeret flens (erat enim scripta amatorie; caput autem litterarum sibi cum illa mima posthac nihil futurum; omnem se amorem abiecisse illim atque in hanc transfudisse), cum mulier fleret uberius, homo misericors ferre non potuit, caput aperuit, in collum inuasit.
} 
de reconhecimento (anagnorisis), que resolve a complicação cômica, e um final feliz com reconciliação. ${ }^{45}$

Antônio parece retratado, enfim, como um estouvado adulescens de comédia. E em outras duas seções das Filípicas, temos:

eu digo, senadores, que atores e atrizes de mimo foram estabelecidos no território da Campânia. (CÍCERO, Phil. 2.101, grifos nossos) ${ }^{46}$

Tu desperdiçaste todo o teu tempo de vida em orgias, comilanças, jogos de azar e vinho, como fazias quando colocavas o queixo e a mente no colo das atrizes de mimo. (CÍCERO, Phil. 13.24, grifos nossos) ${ }^{47}$

Vemos que, não só nessas duas passagens, mas também em outras citadas anteriormente, há referência a atores de mimo e a outras atrizes de mimo, o que pode sugerir que Antônio mantinha, segundo Cícero, relacionamentos com várias atrizes além de Cytheris. Contudo, de acordo com o que expusemos através de alguns trechos das Filípicas, vemos Cícero dando ênfase a Cytheris como amante de Marco Antônio e, para Panayotakis (2006, p. 133),

Nós temos uma atriz que se diz ter desfrutado de grande poder ao lado de Antônio (...). Entretanto, o retrato desfavorável de Cytheris também deveria refletir igualmente mal em Antônio, e visava tanto destruir qualquer crença de que ele se importava com princípios morais de qualquer tipoe demonstrar que ele não era digno de permanecer na arena política. ${ }^{48}$

Podemos dizer, em resumo, que a atriz de mimo Volumnia Cytheris é exposta por Cícero com o objetivo invectivo de difamar a imagem de seu adversário. Ao atribuir à atriz uma imagem negativa e infame, o ethos de Marco Antônio também é prejudicado, levando-se em consideração aqueles que o cercam e o influenciam. Além da atriz de mimo, é interessante citar que Pompeu, litores e comitiva oficial de magistrados são elementos significativos da vida republicana que aparecem contrastados com a degradação moral de Antônio. Para o orador, então, a vida privada de Marco Antônio é infame e, por isso, a imagem da sua vida política/pública também, ou seja, o privado faz com que ele não seja digno de permanecer na política.

\footnotetext{
45 “This particular piece closely resembles a paraklausithyron and narrates Antony's trip home from Gaul, dressed in unusual clothing, to effect, among other objectives, a reconciliation with his wife Fulvia (...). In this brief passage alone we find Antony in many of the personae and situations of comedy. He is a drunk in foolish costume, a young men in love with a meretrix, a repetant philandering husband, and a running slave. We find the comic ingredients of a common taverna, amatory passion, thwarted love, concealed identity, a recognition scene (anagnorisis) which resolves the comic complication, and a happy ending with reconciliation".

${ }^{46}$ Mimos dico et mimas, patres conscripti, in agro Campano collocatos.

47 In lustris, popinis, alea, uino tempus aetatis omne consumpsisses, ut faciebas, cum in gremiis mimarum mentum mentemque deponeres.

48 "We have an actress who is said to have enjoyed great power at Antony's side (...). However, Cytheris' unfavorable portrayal was also meant to reflect equally badly on Antony, and aimed both at demolishing any belief that he cared for moral principles of any kind, and at demostrating that he was unfit to remain in the political arena".
} 


\section{Conclusão}

Neste trabalho, pretendemos mostrar como Cícero tenta prejudicar a imagem política de Marco Antônio também através da crítica e difamação de sua vida privada, expondo de modo crítico a relação deste com o mundo do teatro e, principalmente, com a atriz de mimo Volumnia Cytheris - companheira e amante de Antônio. A infâmia que a atriz carrega simplesmente por fazer parte do mundo dos mimos também influencia na imagem de Marco Antônio, ou seja, associá-lo a Cytheris colabora para o objetivo do orador de construir nos discursos um ethos negativo de Antônio.

Cícero, como vimos, teve um contato positivo com o mundo de teatro através da amizade com Róscio e Esopo e de seu discurso Pro Roscio Comoedo e quando uniu técnicas do teatro à oratória em algumas passagens de seu De oratore. Contudo, a menção ao teatro nas Filípicas - e isso se deve, principalmente, ao objetivo invectivo, crítico e acusativo dos discursos em relação a Marco Antônio - apresenta uma imagem negativa do ambiente teatral (certamente, a que a moral aristocrática tradicional deveria propagar), já que atores e atrizes de mimo, comediantes e demais personagens são associados à persona de Marco Antônio como sendo seus companheiros e citados de modo a difamar a imagem privada - e consequentemente política - de seu adversário.

Assim, para o orador, Marco Antônio está cercado pelo seu chorus de amigos que impedem que ele seja digno da política e muito menos da República. Mais do que isso, ele próprio chega a se comportar, na visão de Cícero, como um caricato personagem cômico, revelando-se, assim, perfeitamente integrado no círculo de atores em que transita.

\section{REFERÊNCIAS}

BEM, L. A. de. Metapoesia e confluência genérica nos Amores de Ovídio. Tese de doutorado. Campinas: Unicamp, 2011.

BLUME, H. (Münster), “Cytheris”, in: Brill's New Pauly, Antiquity volumes edited by: Hubert Cancik, Helmuth Schneider. English Edition: Christine F. Salazar. Classical Tradition volumes edited by: Manfred Landfester. English Edition: Francis G. Gentry. Consulted online on 03 December 2017. First published online: 2006.

CICERO. Epistulae ad familiares. Ed. Shackleton Bailey. Londres: Cambridge University Press, 1977.

In M. Antonium orationes Philippicae XIV. Ed. Paolo Fedeli. 2. Aufl. Stuttgart: B.G. Teubner, 1986.

Cicero. Cambridge, MA; London: Harvard University Press: W. Heinemann, v.6, v.9, v.20, 1989. (The Loeb Classical Library)

Press, 2003.

Philippics I-II. Ed. John T. Ramsey. Cambridge: Cambridge University

. Selected letters. Traduzido por P. G. Walsh. Oxford; New York, NY: Oxford University Press, 2008. 
CICÉRON. De l'orateur. Livre deuxième. Texte établi et traduit par Edmond Courbaud. Paris: Belles Lettres, 1966.

Discours. Tome XIX: Philippiques I à IV. Texte établi et traduit par André Boulanger et Pierre Wuilleumier. Paris: Les Belles Lettres, 1972.

DUNCAN, A. Performance and Identity in the Classical World. NY: Cambridge University Press, 2006.

FANTHAM, E. "Orator et actor". In: EASTERLING, P.; HALL, E. (org.) Atores gregos e romanos: aspectos de uma antiga profissão. Trad. Raul Fiker. São Paulo, SP: Odysseus, 2008, p. 425-442.

HALL, J. "The Philippics". In: Brill's Companion to Cicero: Oratory and Rhetoric. Leiden; Boston; Köln: Brill, 2002, pp. 273-304.

HONORATUS, M.S. In Vergilii carmina comentarii. Servii Grammatici qui feruntur in Vergilii carmina commentarii; recensuerunt Georgius Thilo et Hermannus Hagen. Georgius Thilo. Leipzig. B. G. Teubner, 1881.

JORY, E. J. "Publilius Syrus and the element of competition in the theatre of the republic". In: HORSFALL, N. (ed.). Vir bonus discendi peritus. Londres: Institute of Classical Studies, 1988, pp. 73-81.

KEITH, A. "Lycoris Galli/Volumnia Cytheris: a Greek Courtesan in Rome". Eugesta, n.1, pp. 23-53, 2011.

LEIGH, M. "The Pro Caelio and Comedy". Classical Philology, v. 99, n. 4, pp. 300$335,2004$.

LINTOTT, A. W. Cicero as evidence: a historian's companion. Oxford: Oxford University Press, 2008.

MARONE, P.V. Le Bucoliche. CUCCHIARELLI, Andrea (intr.). Tradução de Alfonso Traina. Roma: Carocci, 2012.

MARSHALL, C. W. The stagecraft and performance of Roman comedy. NY: Cambridge University Press, 2006.

MARCIAL. Martial, Book XIII. Introdução e comentários de Timothy John. London: Duckworth, 2001.

Martial, Buch 8. Struttgart: Franz Steiner, 2002.

MAURÍCIO, S. M. M. Cícero - Em defesa de Célio. Dissertação de Mestrado em Estudos Clássicos, na área de especialização em Mundo Antigo. Departamento de Línguas, Literaturas e Culturas da Faculdade de Letras. Coimbra: Universidade de Coimbra, 2013. 
MCCUTCHEON, R.W. "Cicero's Textual Relations: The Gendered Circulation of Definibus". Helios, v. 43, n. 1, pp. 21-53, 2016.

NÓTARI, T. "El trasfondo jurídico y retórico de la "Pro Caelio" de Cicerón". REHJ, XXXV, pp. 193-212, 2013.

OVIDIO. Ovid. Cambridge, MA; London: Harvard University Press: W. Heinemann, 1977-96.

PANAYOTAKIS, C. "Women in the Greco-Roman mime of the Roman Republic and Early Empire". Ordia Prima, v. 5, pp. 121-139, 2006.

PLUTARCO. Vidas paralelas. Trad. Gilson César Cardoso. Introdução e notas de Paulo Matos Peixoto. Quinto volume. São Paulo, Paumape, 1992.

PRATA, P. O caráter intertextual dos Tristes de Ovídio: Uma leitura dos elementos épicos virgilianos. Tese de doutorado. Campinas: Unicamp, 2007.

PROPÉRCIO. Sexti Properti elegia: Elegias de Sexto Propércio. Org. Guilherme Gontijo Flores. Ed. bilíngue. Belo Horizonte, MG: Autêntica, 2014.

RICHLIN, A. "Approaches to the sources on adultery at Rome”. Women's Studies, v. 8, pp. 225-250, 1981.

SCATOLIN, A. A invenção no Do orador de Cícero: um estudo à luz de Ad Familiares I, 9, 23. Tese (Doutorado em Letras Clássicas). São Paulo: USP, 2009.

SUSSMAN, L. A. "Antony as a Miles Gloriosus in Cicero's second Philippic". Scholia, v. 3, pp. 53-83, 1994.

VIRGILIO. Bucolica georgica. Paris: Alberto Tallone, 1953

Data de envio: 30-03-2018

Data de aprovação: 30-04-2018

Data de publicação: $15-08-2018$ 